\title{
Analgesia-related differences among the erector spinae, multifidus cervicis, and inter-semispinal plane blocks
}

\author{
Yuichi Ohgoshi, MD (D) - Satoshi Terada, MD · Yosuke Usui, MD, PhD • \\ Kenjiro Matsuno, MD, PhD
}

Received: 9 February 2018/Revised: 22 February 2018/Accepted: 23 February 2018/Published online: 5 March 2018

(c) Canadian Anesthesiologists' Society 2018

\section{To the Editor,}

We read with great interest the report by Forero $e t$ al. of an erector spinae plane (ESP) block performed at the level of the third thoracic vertebra (T3) transverse process (T3ESP block) to address chronic shoulder pain. ${ }^{1}$ An ESP block involves injecting local anesthetic (LA) into the fascial plane deep to the erector spinae muscle, where it penetrates the thoracic paravertebral space, resulting in wide truncal analgesia. The T3-ESP block anesthetizes all branches of the spinal nerves - not only in the thoracic region but also in the cervical region (C4 to $\mathrm{T} 5$ ), including the brachial plexus and superficial cervical plexus.

We previously reported multifidus cervicis plane $(\mathrm{MCP})^{2}$ and inter-semispinal plane (ISP) ${ }^{3}$ blocks for perioperative analgesia in cervical spine surgery. The sonographic target for the MCP block is the fascial plane between the multifidus cervicis and semispinalis cervicis muscles, whereas the ISP block target is the fascial plane between the semispinalis cervicis and semispinalis capitis muscles. These blocks can selectively anesthetize the

Y. Ohgoshi, MD ( $\square)$

Department of Anaesthesiology, Keiyu Hospital, Kanagawa, Japan

e-mail: ohgoshi22@gmail.com

\section{S. Terada, MD}

Department of Anaesthesiology, Dokkyo Medical University Saitama Medical Center, Tochigi, Japan

Y. Usui, MD, PhD

Mizutani Pain Clinic, Shizuoka, Japan

Y. Usui, MD, PhD - K. Matsuno, MD, PhD

Department of Anatomy (Macro), Dokkyo Medical University

School of Medicine, Tochigi, Japan medial branches of the dorsal rami of spinal nerves from $\mathrm{C} 4$ to $\mathrm{T} 4 .^{3}$

These articles by Forero $e t$ al. and our own team provide important information regarding spread of the LA injectate and analgesic effects associated with these three blocks. Whereas LA injected to establish a T3-ESP block extends outside (i.e., superficial to) the semispinalis capitis muscle (as shown in Fig. 4 of Forero et al.), injectates used for MCP and ISP blocks spread inside (i.e., deep to) the semispinalis capitis muscle (as the medial branches of the dorsal rami run in this plane) (Figures A, B). The semispinalis capitis muscle runs from the occipital bone to the T6 transverse process, and the injectate spreading alongside this muscle results in cervicothoracic analgesia. However, the semispinalis capitis muscle and its fascia may form a barrier that interferes with the spread of this injectate, which in turn could cause differences in block performance.

To confirm this phenomenon in a Thiel-embalmed cadaver, we injected blue dye (water-based acrylic dye) into the ISP at the C5 level and yellow dye into the ESP at the level of the T5 transverse process. The blue dye (20 $\mathrm{mL}$ ) spread inside the semispinalis capitis muscle to the thoracic region but did not leak outside the muscle (Figure C, left). The yellow dye $(20 \mathrm{~mL})$ spread alongside the longissimus muscle without mixing with the blue dye in the ISP (Figure C, right). Thus, the semispinalis capitis muscle (and surrounding connective tissue) may be a key factor that affects injectate spread.

In conclusion, the semispinalis capitis muscle may cause differences in block performance. MCP and ISP blocks can selectively anesthetize the medial branches of the dorsal rami of spinal nerves from $\mathrm{C} 4$ to $\mathrm{T} 4$, whereas the T3-ESP block anesthetizes all branches of the spinal nerves from 
Figure Transverse

ultrasonographic view of the semispinalis capitis muscle visualized at the level of the fifth cervical vertebra (panel A) and the third thoracic vertebra (panel B). Numbers show the sonographic targets of blocks of the third thoracic vertebra transverse process in the erector spinae plane (arrow 1), multifidus cervicis plane (arrow 2 ), and inter-semispinal plane (arrow 3). Arrow 4 shows the plane where the local anesthetic was identified in the case of Forero et al. Panel C shows cadaver dissection after injection of $20 \mathrm{~mL}$ of blue dye into the inter-semispinal plane (both sides) and $20 \mathrm{~mL}$ of yellow dye into the erector spinae plane (right). The blue dye is visible on the

semispinalis capitis muscle (red line) but does not leak outside the muscle. The yellow dye spreads alongside the inverted longissimus muscle (*). These dyes exist separately. The dashed line shows the dorsal midline, and the double asterisk (**) shows the splenius capitis and splenius cervicis muscles (inverted). $\mathrm{L}=$ longissimus muscle; $\mathrm{M}=$ multifidus cervicis muscle; $\mathrm{SCA}=$ semispinalis capitis muscle; $\mathrm{SCE}=$ semispinalis cervicis muscle; $\mathrm{SP}$ $=$ spinous process $; \mathrm{TP}=$ transverse process
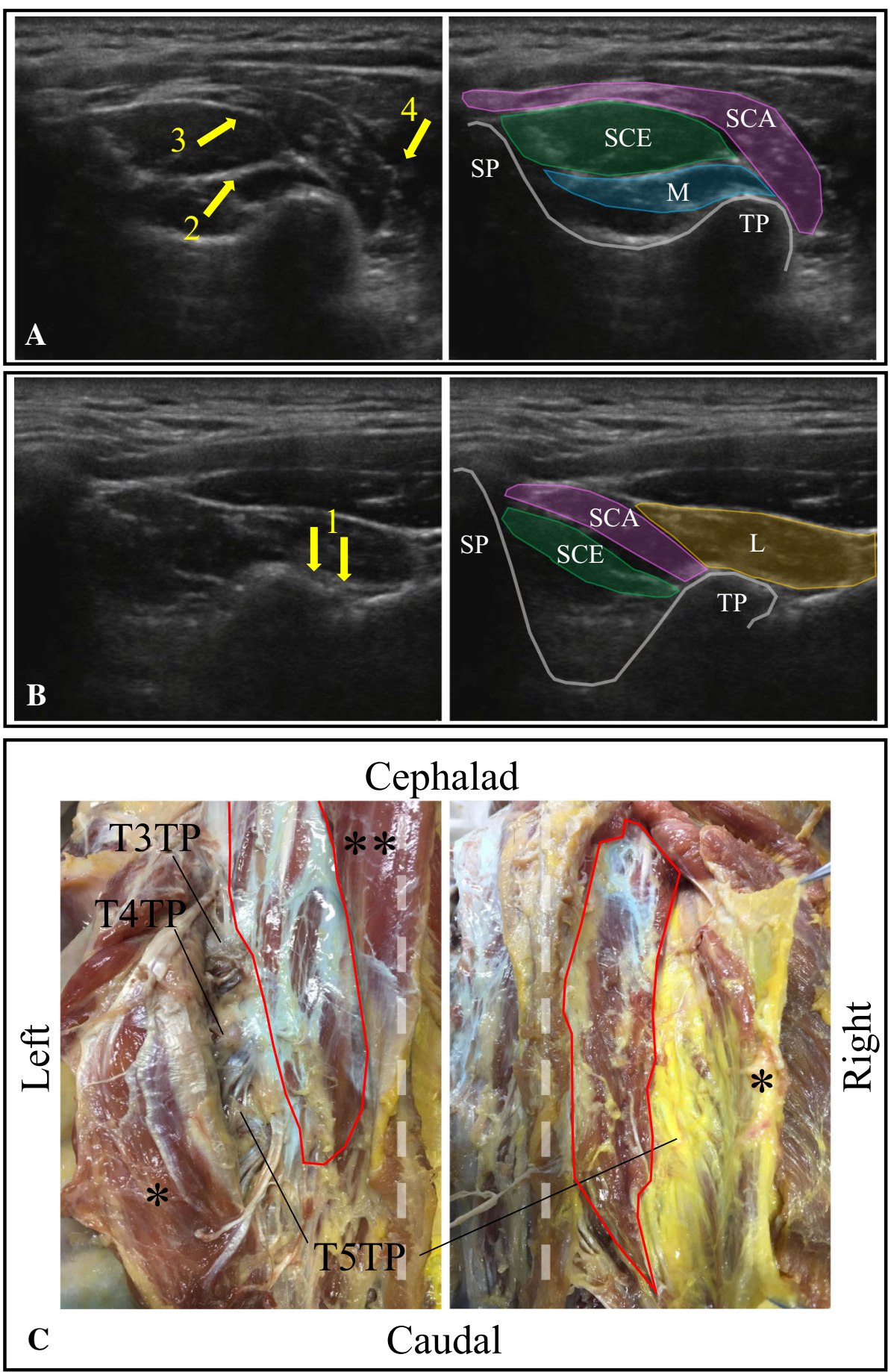

C4 to T5. Using this information, we can select the most appropriate block for a targeted region.

Conflict of interest None declared.

Editorial responsibility This submission was handled by Dr. Hilary P. Grocott, Editor-in-Chief, Canadian Journal of Anesthesia.
Funding None.

Editor's Note The authors of the article: 2017; DOI: https://doi.org/ $10.1007 / \mathrm{s} 12630-017-1010-1$, respectfully declined an invitation to submit a reply to the above letter. 


\section{References}

1. Forero M, Rajarathinam M, Adhikary SD, Chin KJ. Erector spinae plane block for the management of chronic shoulder pain: a case report. Can J Anesth 2017: DOI: https://doi.org/10.1007/s12630017-1010-1.
2. Ohgoshi Y, Izawa H, Kori S, Matsukawa M. Multifidus cervicis plane block is effective for cervical spine surgery. Can J Anesth 2017; 64: 329-30

3. Ohgoshi $Y$, Nishizakura R, Takahashi $Y$, et al. Novel ultrasoundguided inter-semispinal plane block: a comparative pilot study in healthy volunteers. J Anesth 2018; 32: 143-6. 